\title{
Retrieval operations in cued recall and recognition
}

\author{
RONALD P. FISHER \\ Erindale College, University of Toronto, Toronto, Ontario, Canada
}

\begin{abstract}
The present study compared the effects of two classes of experimental manipulations on the recognition and cued recall of target words learned in the presence of list cues. One class of manipulations, learning instructions (repetition vs. meaningful rehearsal), had similar effects on recall and recognition, whereas the other, preexperimental association between target and cue words, had separable effects: Cue-to-target association affected only recall, while target-to-cue association affected only recognition performance. Recall and recognition were thus viewed as fundamentally similar processes, both of which require retrieval operations. Differences between the two were attributed to the differential abilities of the recall and recognition retrieval cues to access the original episodic event.
\end{abstract}

Most of the earlier attempts to explain recallrecognition differences were founded on the assumption that recognition is inherently easier. Consequently, these explanations were quantitative in nature. For example, various "strength" theorists postulated that the decision process in the recognition test is based on a lower threshold than in the recall test (Bahrick, 1965; Postman, Jenkins, \& Postman, 1948). More recently, different versions of the "two-process (generaterecognize)" theories suggested that recognition is easier because an additional retrieval operation is required to successfully recall an event than to recognize it (Anderson \& Bower, 1972; Kintsch, 1970). The recent work of Tulving and his colleagues (Tulving \& Thomson, 1973; Watkins \& Tulving, 1975), however, demonstrates that under a variety of conditions, recall is either no worse or is better than recognition. Differences between the two, then, cannot be thought of solely in quantitative terms, since recognition is not inherently any easier than recall.

A different approach to the problem is to compare the two along a qualitative dimension. The most obvious place to start the search is with the different retrieval information used in the two paradigms: In recall a contextual cue is provided, whereas in recognition a copy of the target item is provided. If memory behavior is to be determined, at least in part, by the extent to which the information in the retrieval cue overlaps or accesses the information in the encoded trace (Lockhart, Craik, \& Jacoby, 1976; Tulving, 1974), then it is reasonable to expect that under some conditions,

This research was supported by Grant A8261 from the National Research Council of Canada to Fergus Craik. I would like to thank Fergus Craik and Eileen Simon for their helpful comments on an earlier draft. Requests for reprints should be sent to Ronald Fisher, Department of Psychology, Florida International University, Tamiami Campus, Miami, Florida 33199. a contextual cue may be more efficient than a copy of the target. That is, there is no a priori reason why a copy of the target item must be more successful in accessing the information contained in the encoded trace than is a contextual cue. An implicit assumption of this approach is that the encoded trace is not simply a replica of the nominal target, but that it is the result of whatever cognitive operations are performed on the target and its contextual environment (Anderson \& Bower, 1972; Lockhart et al., 1976; Tulving, 1976).

The present study makes no attempt to critically test different mechanisms to account for the effects of informational overlap between the encoded trace and the retrieval cue. Instead, this principle serves as a perspective from which to view memory behavior, and it leads to the following argument. In the present context, there are three information sources that may overlap: the encoded trace, the recall cue, and the recognition cue. Recall performance is related to the overlap between the encoded trace and the recall cue, and recognition is related to the overlap between the encoded trace and the recognition cue. If the information contained in the recall and recognition cues can be manipulated independently, then there should be some factors that affect recall but not recognition performance and others that affect recognition but not recall. That is, any factor that affects only the copy cue's ability to access or overlap the encoded trace will affect only recognition performance. Conversely, any factor that affects only the contextual cue's ability to access or overlap the encoded trace will affect only recall performance.

For the purposes of translating these ideas into an experimental format, consider Bartlett's (1932) suggestion that one's recollection of an event is the product of his elaboration of the retrieval information. This elaboration or reconstruction is guided by the preexperimental storehouse of information (semantic 
memory) about the retrieval cue, in particular, its relation to the desired episodic trace. The more accessible the preexperimental association between the retrieval cue and the encoded episodic trace, the more accurate will be the reconstruction. In this respect it is assumed that recall and recognition function in similar fashion. Differences between these two forms of memory arise from the different retrieval cues available: In recall, the retrieval cue is a contextual one, whereas in recognition, the retrieval cue is a nominal copy of the target item. It is expected, therefore, that the preexperimental association from the contextual cue to the information in the episodic event (target plus context) should affect the ability to recall the original event, whereas the preexperimental association from the target item to the information in the episodic event should affect the ability to recognize the original event.

These notions about the effects of preexperimental associations between the information in the retrieval cue and the encoded event were tested in the following manner. Subjects were induced to learn a series of target words, each in the context of another cue word, so that the encoded trace was some composite of the target plus the cue words. These target-cue pairs were selected so that the preexperimental association from the cue to the target word was either high or low; that is, the encoded event (target plus cue) was either easily generated from the cue word (high cue-to-target association) or difficult to generate from the cue word (low cue-to-target association). It was expected that this manipulation would affect only cued recall performance. A second set of target-plus-cue word pairs was selected so that the preexperimental association from the target to the cue word was either high or low; thus, the original event was either easy or difficult to generate from the target word. It was expected that this manipulation would affect only recognition performance.

\section{EXPERIMENT 1}

\section{Method}

Stimuli. Each word pair consisted of a target word printed in uppercase letters and a cue word in lowercase letters. There were 48 critical word pairs that were equally divided into four types: $\mathrm{Hi}-\mathrm{Hi}$-Both the target and cue words mutually elicited each other with high probability in a preexperimental free association test (e.g., window-GLASS); Lo-Lo-the target and cue words mutually elicited each other with low probability in the free association test (e.g., bath-KING); Lo-Hi-the cue word elicited the target word with low probability, but the reverse association occurred with high probability (e.g., catLION); $\mathrm{Hi}-\mathrm{Lo}-$ the cue word elicited the target word with high probability, but the reverse association occurred with low probability (e.g., cabbage-HEAD).

The preexperimental free association data were taken from the Keppel and Strand (1970) and Palermo and Jenkins (1964; college group) norms, such that the criterion for high probability of elicitation was at least $3.3 \%$ of the responses; the criterion for low-probability associations was less than $1.1 \%$ of the responses. The median probability of elicitation was .092 for the highprobability associations and .000 for the low associations. All target words were high-frequency nouns (Thomdike-Lorge, 1944 , count of at least $24 /$ million) with target word frequency approximately equated across word types (see Table 1 for a listing of all the target-cue pairs).

Table 1

Target-Context Word Pairs

\begin{tabular}{|c|c|c|c|c|}
\hline \multirow[b]{2}{*}{ Context Word } & \multirow[b]{2}{*}{ Target Word } & \multirow[b]{2}{*}{$\begin{array}{c}\text { Target Word } \\
\text { Frequency }\end{array}$} & \multicolumn{2}{|c|}{ Probability of Preexperimentally Eliciting } \\
\hline & & & $\begin{array}{c}\text { Target from } \\
\text { Context Word }\end{array}$ & $\begin{array}{c}\text { Context Word } \\
\text { from Target }\end{array}$ \\
\hline \multicolumn{5}{|c|}{ Hi-Hi Word Pairs } \\
\hline health & DOCTOR & AA & .042 & .075 \\
\hline train & WHISTLE & A & $.093^{*}$ & .106 \\
\hline nail & FINGER & $\mathbf{A A}$ & $.088^{*}$ & .047 \\
\hline law & JUDGE & AA & $.044^{*}$ & $.099 *$ \\
\hline sleep & NIGHT & AA & .042 & $.038^{*}$ \\
\hline sour & LEMON & 27 & .107 & $.264^{*}$ \\
\hline circle & SQUARE & $\mathrm{AA}$ & $.253^{*}$ & .143 \\
\hline sweet & CANDY & 32 & .159 & $.346^{*}$ \\
\hline steal & THIEF & 28 & $.093^{*}$ & .264 \\
\hline snow & MOUNTAIN & $\mathrm{AA}$ & $.033^{*}$ & .072 \\
\hline window & GLASS & AA & .216 & $.099^{*}$ \\
\hline carpet & RUG & 40 & $.311^{*}$ & $.115^{*}$ \\
\hline \multicolumn{5}{|c|}{ Lo-Lo Word Pairs } \\
\hline $\operatorname{dir} t$ & WOOL & A & $.000^{*}$ & $.000^{*}$ \\
\hline smooth & FLOOR & $\mathbf{A A}$ & .001 & $.000^{*}$ \\
\hline bath & KING & AA & .000 & .000 \\
\hline hair & NEEDLE & 34 & $.000 *$ & .001 \\
\hline stove & LAMP & A & .001 & .000 \\
\hline command & CITY & $\mathbf{A A}$ & .000 & .000 \\
\hline quiet & SKY & AA & .000 & $.000^{*}$ \\
\hline trouble & BOOK & AA & .001 & $.000^{*}$ \\
\hline stand & CROWD & AA & .001 & $.006^{*}$ \\
\hline bed & SHOE & AA & .000 & $.000^{*}$ \\
\hline dry & EARTH & AA & $.000^{*}$ & .001 \\
\hline dream & BUTTERFLY & 22 & .000 & .000 \\
\hline
\end{tabular}


Table 1 Continued

\begin{tabular}{|c|c|c|c|c|}
\hline \multirow[b]{2}{*}{ Context Word } & \multirow[b]{2}{*}{ Target Word } & \multirow[b]{2}{*}{$\begin{array}{l}\text { Target Word } \\
\text { Frequency }\end{array}$} & \multicolumn{2}{|c|}{ Probability of Preexperimentally Eliciting } \\
\hline & & & $\begin{array}{l}\text { Target from } \\
\text { Context Word }\end{array}$ & $\begin{array}{c}\text { Context Word } \\
\text { from Target }\end{array}$ \\
\hline \multicolumn{5}{|c|}{ Lo-Hi Word Pairs } \\
\hline food & TABLE & AA & $.000^{*}$ & .059 \\
\hline eat & STOMACH & 30 & $.000^{*}$ & .092 \\
\hline black & SPIDER & 24 & $.000^{*}$ & .055 \\
\hline cat & LION & A & $.000^{*}$ & .050 \\
\hline man & PRIEST & 42 & .000 & .066 \\
\hline gun & SOLDIER & AA & .008 & .091 \\
\hline hard & HAMMER & 34 & .000 & .042 \\
\hline soft & BUTTER & AA & .001 & .054 \\
\hline yellow & CHEESE & 45 & .002 & .071 \\
\hline house & COTTAGE & 46 & .002 & .264 \\
\hline smoke & TOBACCO & 36 & $.000^{*}$ & .482 \\
\hline song & MUSIC & AA & $.022 * \dagger$ & .164 \\
\hline \multicolumn{5}{|c|}{ Hi-Lo Word Pairs } \\
\hline car & DOOR & AA & .034 & $.000^{*}$ \\
\hline eagle & BIRD & $\mathrm{AA}$ & .576 & $.006^{*}$ \\
\hline chair & LEG & AA & .035 & $.006^{*}$ \\
\hline mutton & LAMB & 45 & .317 & $.000^{*}$ \\
\hline citizen & PERSON & AA & .122 & $.000^{*}$ \\
\hline street & LIGHT & $\mathbf{A A}$ & .057 & $.011^{*}$ \\
\hline blossom & APPLE & A & .090 & $.000^{*}$ \\
\hline baby & GIRL & AA & .045 & .000 \\
\hline stem & PLANT & AA & .201 & $.006^{*}$ \\
\hline blue & WATER & $\mathbf{A A}$ & .034 & $.006^{*}$ \\
\hline moon & STAR & $\mathbf{A A}$ & .239 & .011 \\
\hline cabbage & HEAD & $\mathbf{A A}$ & .071 & .004 \\
\hline
\end{tabular}

Note-Target word frequency $=$ Thorndike-Lorge (1944) G count. norms (all others are from Palermo \& Jenkins, 1964, norms).

Elicitation probability is from Keppel and Strand (1970) tExceeds criterion for low probability of elicitation (.011).

Procedure. All of the subjects were initially given a setinducing task in which 20 target-cue pairs were presented at a 5 -sec rate. The subjects were instructed to learn the words in uppercase letters in terms of the context of the other word on the stimulus card. After the last word pair, a cued recall test was given in which the cue words were presented individually as the retrieval cues, and the subjects were to write the associated target words. Subjects were allowed $8 \mathrm{sec}$ per retrieval cue to make the appropriate response.

After the initial task, the subjects were divided evenly into a recall and a recognition group. Both groups were presented with 54 word pairs at a 5 -sec rate. Immediately after the last pair, the recall group received a cued recall test in which the list cue words were presented individually as the retrieval cues; the subjects were given $8 \mathrm{sec}$ per retrieval cue to write the appropriate target word. Those in the recognition group were given a test sheet containing the 48 target words that had been presented plus 144 foils. The subjects were given unlimited time and were instructed to circle the 48 target words they had just learned; all subjects were asked to make exactly 48 responses. Shortly after this test, half of the subjects in the recognition group were given a cued recall test of the same word pairs; this test was identical to that received by the recall group.

Subjects and Design. Forty-eight Erindale College students of both sexes served as paid volunteers: 24 were assigned to the recall group and 24 to the recognition group. Only the last 12 subjects in the recognition group received the additional cued recall test.

The subjects in both groups saw the identical list of 54 word pairs on the data collection trial. The middle 48 word pairs, which were later tested, were randomly ordered with the constraint that every block of 4 word pairs contain one member from each word pair type: Hi-Hi, Lo-Lo, Lo-Hi, and Hi-Lo. Two different random orders were used in the experiment. In the recall test, the order of testing matched the input order so that a constant presentation-test lag obtained for all word pairs. In the recognition test, the 48 target words were randomly dispersed among the 144 foils. The foils and targets were matched for word frequency, so that for every target there were three foils of similar frequency.

\section{Results}

For the recall tests, a response was scored as correct only if the target word was given as the response to the appropriate cue word. (Fewer than 3\% of all the responses were intralist intrusions.) In the recognition test, all the subjects complied with the instructions to make exactly 48 "old" responses.

The recall (recall group) and recognition scores for the four word-pair types are presented in Table 2. As expected, recall performance was directly related to the preexperimental association from the cue word to the target $[F(1,23)=51.7, p<.01]$, whereas the reverse association, target to cue, had no effect $[F(1,23)=1.1$, $p>.25]$. On the other hand, recognition scores were directly related to the association from the target to the cue word $[F(1,23)=53.0, p<.01]$, but there was no effect of the reverse association, cue to target $[F(1,23)=1.3, p>.25]$. Both two-way interactions, Cue to Target by Test and Target to Cue by Test, were reliable $[F(1,46)=48.9, p<.01$, and $F(1,46)=17.8$, $\mathrm{p}<.01$, respectively] 
Since a different set of 12 target words was used for each of the word-pair types, the possibility exists that the observed differences are due only to the differential recallability and recognizability of the target words in the four word-pair types. For example, the Hi-Hi word pairs might be better recalled and recognized than the Lo-Lo word pairs simply because the Hi-Hi target words are remembered better than the Lo-Lo targets. In order to test for this potential artifact, a brief experiment was conducted in which the 48 target words were shown as isolated units, that is, not in the presence of the cue words, to an independent group of 10 subjects, who attempted to recognize and free recall as many of these words as possible. There were no differences in the hit rates among the four groups of words used in the main experiment $[\mathrm{Hi}-\mathrm{Hi}=.69, \mathrm{Lo}-\mathrm{Hi}=.73, \mathrm{Hi}-\mathrm{Lo}=.68$, Lo-Lo $=.73 ; F(3,27)<1]$, and there were no differences in the free recall scores $[\mathrm{Hi}-\mathrm{Hi}=.33, \mathrm{Lo}-\mathrm{Hi}=.48$, $\mathrm{Hi}-\mathrm{Lo}=.38, \mathrm{Lo}-\mathrm{Lo}=.42 ; \mathrm{F}(3,27)=2.7, \mathrm{p}>.05]$.

A comparison between the recall (of the recall group) and recognition scores shows that recognition $[\mathrm{p}($ hit $)=.72]$ was generally superior to recall $[\mathrm{p}$ (correct recall $)=.55]$; however, this was not necessarily the case across all word pairs: For the Hi-Lo word pairs, recall $[\mathrm{p}($ correct recall $)=.68]$ was better than recognition $[\mathrm{p}(\mathrm{hit})=.61]$. A finer grain analysis of recall vs. recognition differences comes from following the fate of an individual item for a given subject across the two tests. The following analyses are based on the scores of those 12 subjects in the recognition group who performed the recall test after having completed the recognition test. For our purposes, the critical statistic is the probability of recalling a target word when the cue word is supplied, given that the target word was not recognized in the earlier test. For the four word-pair types, these probabilities were .34 (15/44: Hi-Hi), .48 (29/60: Hi-Lo), .09 (3/32: Lo-Hi), and .05 (3/55: Lo-Lo). That is, under appropriate recall conditions, when the retrieval cue generated the target with high probability, a large proportion of words that were not recognized could be recalled.

When the recall scores of these 12 subjects (recognition group) are conditionalized on correct earlier recognition, the probabilities of recall for the four word-pair types are $.80(80 / 100$ : Hi-Hi), $.86(72 / 84$ : Hi-Lo), .57 (64/1 12: Lo-Hi), and .52 (46/89: Lo-Lo). Two sets of relations should be noted when comparing these scores to the previously mentioned conditional scores. First, for each word-pair type, the level of recall is higher when conditionalized on recognition success than when conditionalized on recognition failure, indicating some general factor that contributes to both recall and recognition. Second, recall is relatively good for the Hi-Hi and Hi-Lo word pairs and poor for the Lo-Hi and Lo-Lo word pairs whe the r conditionalized on recognition success or recognition failure, indicating some factor that is specific to the recall test.
Table 2

Cued Recall and Recognition Accuracy of Word Pairs in Experiment 1

Cue-to-Target Association

\begin{tabular}{cccccccc} 
& \multicolumn{4}{c}{ Cue-to-Target Association } \\
\cline { 2 - 4 } $\begin{array}{c}\text { Target-to- } \\
\text { Cue Associ- } \\
\text { ation }\end{array}$ & Low & High & Mean & Low & High & Mean \\
\hline Low & .39 & .68 & .54 & .69 & .61 & .65 \\
High & .47 & .65 & .56 & .82 & .76 & .79 \\
Mean & .43 & .67 & & .76 & .69 & \\
\hline
\end{tabular}

Note-Recall refers to the probability of correct recall; recognition refers to the probability of a hit.

\section{Discussion}

The results of this experiment corroborated the expectation that the preexperimental association from cue to target would affect only cued recall performance (Humphreys \& Galbriath, 1975) and that the preexperimental association from target to cue would affect only recognition. What appears most striking about these findings is not so much the difference between recall and recognition, but the similarity between them. In both cases, high preexperimental association from the retrieval cue to the encoded trace led to better retention than did low association. In the recognition task, where the retrieval cue was a nominal copy of the target, the effective retrieval manipulation was the association from the target (to cue). In recall, where the retrieval cue was a list cue, the effective retrieval manipulation was the association from the cue (to target). It appears that both effects are alternate versions of the same general principle that memory for an event is related to the ease of reconstructing the event from the retrieval cue. Generally, this reconstruction operation has been interpreted as being a retrieval function. If we are to consistently apply this interpretation, we are led to the conclusion that retrieval is a component of both recall and recognition.

The view that recall and recognition are similar in nature and differ primarily on the basis of the information contained in their respective retrieval cues has been endorsed recently by several investigators (e.g., Flexser \& Tulving, 1978; Lockhart et al., 1976; Rabinowitz, Mandler, \& Patterson, 1977), all of whom maintain that successful memory in both paradigms is related to the degree to which the retrieval cue accesses or overlaps the information in the originally encoded trace. Two related expectations emerge from this view. First, as previously mentioned, if the information in the contextual and copy cues are independent, then the recallability and recognizability of an event can be manipulated separably. Second, if the encoded trace being accessed is identical for the two tasks, an experimental manipulation that alters the encoded trace should have correlated effects on recall and recognition. Any learning manipulation that makes the encoded event generally more accessible, that is, from a variety of retrieval cues, 
should support better recall and recognition. This may be conceptualized in any of several ways, depending upon one's theoretical framework of the mechanism responsible for "informational overlap." Suppose, for example, that informational overlap between the encoded trace and the retrieval cue is directly related to the number of features shared by the two such that the greater the number of common features, the more likely is recollection of the original event (Flexser \& Tulving, 1978). A learning manipulation that increases the number of encoded features of the original event should thereby make it more retrievable when any of several (e.g., recall and recognition) cues are used.

In Experiment 1 no attempt was made to implement an experimental manipulation that would have similar effects on recall and recognition, so this suggestion is not directly testable from the data of the first experiment. However, an analysis of the conditional recall scores tends to confirm this idea: For all four word-pair types, cued recall of the target word was higher when conditionalized on successful recognition of the target than when conditionalized on failure to recognize the target. Now, one may wish to argue that this positive correlation between recall and recognition scores reflects in part the contribution of some "artifact" like item selection (there is some inherent characteristic of certain word pairs that makes them relatively easy to learn) or some attentional factor (e.g., the subject pays more attention to some word pairs than others and thus learns them better). However, this is in perfect agreement with the suggestion presented here; namely, the encoded trace that the learner attempts to access is identical for recall and recognition tests. As such, whatever makes the trace generally more accessible, whether it is a property of the item to be learned or a characteristic of the learner, will benefit both recall and recognition performance (Flexser \& Tulving, 1978; Rabinowitz et al., 1977).

The results of Experiment 1 partially support the suggestion that two separate classes of experimental manipulations exist, one of which has separable effects on recall and recognition, and the other correlated effects. In order to more appropriately test this idea, in Experiment 2 both classes of experimental manipulations were directly implemented. First, preexperimental target-to-cue and cue-to-target associations were again expected to have separable effects on recognition and recall. Second, learning instructions, whether to learn the pair of words by repetition or by forming a meaningful relation between the two words, were expected to yield correlated effects on recall and recognition. Meaningful learning was expected to yield a richer, more elaborate trace and thereby support better recall and recognition (see Fisher \& Craik, Note 1 ).

\section{EXPERIMENT 2}

\section{Method}

Subjects and Design. The basic design of Experiment 2 was similar to that of Experiment 1 with the exception that an additional variable, learning instructions, was introduced. Forty-eight male and female Erindale College students participated in this experiment. Twenty-four subjects were instructed to learn the word pairs by repeating the pairs to themselves (repetition), and 24 subjects were instructed to learn the word pairs by creating meaningful relations between the two words (meaningful). Before the word pairs were presented, the experimenter suggested various types of meaningful relations that the subjects might use (e.g., making up phrases or sentences containing the two words, generating interactive images of the two words, finding categorical relationships or words that are common associates of both words in the pair).

Procedure. All subjects were told that they would see a series of word pairs and that they should study these pairs as units, since they would be later tested on them. The subjects were not told which member of the pair would be the test item. The same set of 54 stimulus cards that was used in Experiment 1 was presented at a 6-sec rate.

After the last word pair was presented, all the subjects received a cued recall and a recognition test. Test order was counterbalanced across subjects. The target words, retrieval cues, and foils were identical to those used in Experiment 1. In the recognition test, the subjects were given unlimited time and were permitted to indicate as many "old" items as they wished. In the cued recall test, the subjects were permitted $7.5 \mathrm{sec}$ per retrieval cue to write the appropriate response.

\section{Results and Discussion}

A preliminary analysis showed no main effect of test order, whether recall preceded or followed the recognition test $(F<1)$, and no reliable interaction between order and test (recall vs. recognition) $[F(1,44)=3.00$, $p>.05]$. Unless otherwise indicated, the following analyses are based upon the scores collapsed across the two test orders.

The effects of preexperimental cue-to-target and target-to-cue associations on recall and recognition can be seen in Table 3 ; they closely resemble the pattern of data in Experiment 1. Recall performance was directly related to cue-to-target association, whereas recognition performance was directly related to target-to-cue association. The difference between the probabilities of correct recall for high and low cue-to-target associations $(.70$ vs. .44$)$ was statistically reliable $[F(1,46)=178.6$, $\mathrm{p}<.01]$, as was the difference between the probabilities of a hit (recognition) for high and low target-to-cue associations $(.76$ vs. .59) $[\mathrm{F}(1,46)=95.5, \mathrm{p}<.01]$. These patterns of data were found both in the meaningful and the repetition groups, the only difference being that scores were generally higher for meaningful than for repetition instructions. Although the general patterns

Table 3

Cued Recall and Recognition Accuracy of Word Pairs (Averaged Across Learning Instructions) in Experiment 2

\begin{tabular}{cccccccc}
\hline & \multicolumn{4}{c}{ Cue-to-Target Association } \\
\cline { 2 - 4 } \cline { 5 - 7 } $\begin{array}{c}\text { Target-to- } \\
\text { Cue Associ- } \\
\text { ation }\end{array}$ & Low & High & Mean & & Low & High & Mean \\
\cline { 2 - 4 } \cline { 5 - 8 } \\
\hline Low & .40 & .69 & .54 & & .65 & .53 & .59 \\
High & .48 & .71 & .59 & & .78 & .74 & .76 \\
Mean & .44 & .70 & & & .72 & .64 & \\
\hline
\end{tabular}

Note-Recall refers to the probability of correct recall; recognition refers to the probability of a hit. 
of data are similar for Experiments 1 and 2 (compare Tables 2 and 3), the interpretation of Experiment 2 is somewhat problematic, as there was a marginally reliable effect of target-to-cue association in recall $[F(1,46)=5.90, p<.05]$ and a cue-to-target effect in recognition $[F(1,46)=20.58, p<.01]$. The impact of these effects, however, is mitigated by their relatively small magnitudes. In the recall scores, the difference between high and low target-to-cue association (.59 vs. .54) accounts for less than $1 \%$ of the total variance. Similarly, in the recognition scores, the difference between high and low cue-to-target association (.64 vs. .72) accounts for only $3 \%$ of the total variance. (Note also that the difference is in the "wrong" direction: Low cue-to-target association is better than high.) The conclusion, then, remains basically the same as in Experiment 1: Recall and recognition are separable in that some manipulation (cue to target) has a greater effect on recall than on recognition, but another manipulation (target-to-cue association) has a greater effect on recognition than on recall. The two two-way interactions that are required to support this conclusion, Cue to Target by Test and Target to Cue by Test, were both statistically reliable $[\mathrm{F}(1,46)=244.6, \mathrm{p}<.01$, and $\mathrm{F}(1,46)=35.8, \mathrm{p}<.01$, respectively $]$.

A simple way to illustrate this conclusion and the two-way interactions is to compare the recallability and recognizability of the Hi-Lo and Lo-Hi pairs. Both word pairs are asymmetric, with Hi-Lo being accessed better by the list cue and the Lo-Hi by the copy cue. In general, Hi-Lo word pairs were the better recalled, whereas Lo-Hi pairs were the better recognized. The identical relation between Hi-Lo and Lo-Hi pairs also obtained in Experiment 1 (see Table 2). ${ }^{1}$

The second issue of concern in Experiment 2 was whether a different variable, leaming instructions, would affect recall in the same way as it affected recognition. For both recall and recognition tests, meaningful instructions supported better retention than did repetition instructions: $p$ (correct recall) was .71 vs. .43 and p(hit) was .77 vs. .59 in favor of meaningful instructions. Both of these differences are statistically reliable $[F(1,46)=42.5, p<.01$, for recall; $F(1,46)=18.7$, $\mathrm{p}<.01$, for recognition]. There was a slightly larger effect of learning instructions on the recall than on the recognition scores $[\mathrm{F}(1,46)=10.4, \mathrm{p}<.01]$; however, it is difficult to interpret this interaction, as the two tests employ different dependent measures and the interaction was not a crossover.

The observation that meaningful leaming supported better retention than did repetition learning is hardly unexpected in light of the empirical findings on the issue of maintenance vs. elaborative rehearsal strategies (e.g., Craik \& Lockhart, 1972; Mazuryk \& Lockhart, 1974). The purpose of instituting this particular experimental manipulation was not to critically analyze Craik and Lockhart's levels-of-processing notions, but to demonstrate that at least some learning manipulation has similar effects on recall and recognition, while another type of manipulation has separable effects on the two tasks. Presumably, the same type of results would have emerged had another manipulation (e.g., study time) been substituted for learning instructions.

The strategy underlying the present study was similar to that of McCormack (1972); only the results and interpretation are different. McCormack observed only two types of manipulations, those that had similar effects on recall and recognition and those that affected recall but not recognition, and thereby concluded that a retrieval operation was required only for the recall of an event. In the present study, a third type of variable was also observed, one that affects recognition and not recall. The relation between this manipulation (target-tocue association) and the one that affects recall but not recognition (cue-to-target association) becomes clearer when they are both recast into the more general terms of the association from the retrieval cue to the original event. That is, they both appear to be versions of the same general principle that memory of an event is related to the ease of reconstructing the event from the retrieval cue. Target-to-cue association is the appropriate form when the retrieval cue is the target item (recognition), and cue-to-target association is the appropriate form when the retrieval cue is the list cue (recall).

A reasonable account of the foregoing data is provided by the recent model of Flexser and Tulving (1978), in which it is assumed that performance in both recall and recognition tasks is directly related to the number of overlapping features between the encoded input trace and the retrieval cue. As the number of overlapping features between the encoded input trace and the list cue or between the input trace and the copy cue increases, recall and recognition performance improve. Since the encoded input trace is assumed to be identical for the recall and recognition tests, any learning manipulation that increases the number of encoded input features, "goodness of encoding," will increase the number of features that may potentially overlap with the list or copy cues and thus lead to better recall and recognition performance. When the encoding of an input event is fixed, the recallability and recognizability of this event can be manipulated by making the retrieval cue more or less similar (number of overlapping features) to the input trace. Since the features in the list and copy cues are assumed to be independent, the similarity between the list cue and the input trace, the recallability of the event, can be manipulated without affecting the recognizability of the event. Similarly, one can manipulate the recognizability without altering the recallability of the event. The Flexser and Tulving model thus adequately accounts for the observed findings that some manipulations lead to correlated recall-recognition performance (learning instructions) but other manipulations lead to uncorrelated recall-recognition performance (cue-to-target and target-to-cue associations).

A second aspect of the present data that the Flexser 
and Tulving (1978) model addresses is the conditional recognition score, the likelihood of recognizing a target given that it could be successfully recalled from the list cue. This model is based on the observation by Tulving and Wiseman (1975) that in a wide variety of experiments conforming to the "recognition failure" paradigm, presentation of cue-target word pairs followed by a recognition test followed by a cued recall test of the target, the conditional accuracy rate, $\mathrm{p}(\mathrm{rgn} \mid \mathrm{rcl})$, is predictable from the overall recognition hit rate, $p(r g n)$. The formula that relates these two measures is $\mathrm{p}(\mathrm{rgn} \mid \mathrm{rcl})=\mathrm{p}(\mathrm{rgn})+.5\left[\mathrm{p}(\mathrm{rgn})-\mathrm{p}(\mathrm{rgn})^{2}\right]$. This function, according to Tulving and Wiseman, is relatively unaffected by the overall levels of recall and recognition performance, and it is the regularity of this function that the Flexser and Tulving model seeks to explain. In terms of explaining the present data, the Flexser and Tulving model is successful only to the extent that the present data conform to the Tulving and Wiseman equation.

Since the Tulving and Wiseman (1975) equation is based on those studies in which the recognition test precedes the cued recall test, only the data from that order of testing in the present study are included in the following analysis. When these data are analyzed as a whole (i.e., collapsed across learning instruction and target-to-cue and cue-to-target associations), the resulting point, $\mathrm{p}(\mathrm{rgn})=.68$ and $\mathrm{p}(\mathrm{rgn} \mid \mathrm{rcl})=.79$, fits squarely on the Tulving and Wiseman function. However, when the data are further reduced into repetition vs. meaningful instructions, low vs. high target-to-cue association, and low vs. high cue-to-target association (see Table 4), there begins to emerge a distinct pattern of deviations from the function. Namely, in those conditions where recall performance was relatively poor, repetition instruction and low cue-to-target pairs, the conditional recognition scores were higher than those predicted by the Tulving and Wiseman equation. When recall performance was relatively good, as with meaningful instructions and high cue-to-target pairs, the conditional recognition scores were lower than those predicted by the equation. For example, in the repetition instruction group, the conditional recognition hit rate (.74) was .03 above the rate predicted from the overall recognition hit rate (.59), whereas in the meaningful instruction group, the conditional hit rate (.82) was .05 below the rate predicted from the overall recognition hit rate $(.78)$. This is not simply a result of averaging across subjects, since 8 of the 12 repetition subjects were on or above the Tulving and Wiseman function, whereas all 12 of the meaningful subjects were on or below the function. Similarly, for the low cue-to-target word pairs, the conditional recognition rate was considerably above (.07) the function, whereas for the high cue-to-target word pairs, the conditional hit rate was slightly below (.02). These deviations from the function appear to be systematically related to the probability of recall, since when the data are reduced into low vs. high target-to-cue pairs, a manipulation that has little or no effect on recall, the points lie almost exactly on the function (see Table 4). Thus, to the extent that the present data systematically deviate from the Tulving and Wiseman function, the Flexser and Tulving (1978) model cannot account for the conditional recognition scores.

\section{CONCLUSION}

The direction of the present argument was to focus on the role of retrieval operations in both recall and recognition, paralleling recent efforts by Anderson and

Table 4

Comparison of Observed and Predicted Recognition Accuracy Rates from Tulving and Wiseman (1975) Equation

\begin{tabular}{|c|c|c|c|c|c|}
\hline & $\mathrm{p}(\mathrm{rcl})$ & $\mathrm{p}(\mathrm{rgn})$ & $\begin{array}{l}\text { Observed } \\
\text { p(rgn|rcl) }\end{array}$ & $\begin{array}{l}\text { Predicted } \\
\mathrm{p}(\mathrm{rgn} \mid \text { Icl })\end{array}$ & $\begin{array}{c}\text { Observed - } \\
\text { Predicted }\end{array}$ \\
\hline & \multicolumn{5}{|c|}{ Repetition Condition } \\
\hline $\begin{array}{l}\text { Lo-Lo } \\
\text { Lo-Hi } \\
\text { Hi-Lo } \\
\text { Hi-Hi }\end{array}$ & $\begin{array}{l}.24 \\
.31 \\
.63 \\
.65\end{array}$ & $\begin{array}{l}.62 \\
.64 \\
.46 \\
.63\end{array}$ & $\begin{array}{l}.91 \\
.89 \\
.62 \\
.74\end{array}$ & $\begin{array}{l}.74 \\
.76 \\
.58 \\
.75\end{array}$ & $\begin{array}{r}.17 \\
.13 \\
.04 \\
-.01\end{array}$ \\
\hline \multirow[t]{2}{*}{ Average } & .45 & .59 & .74 & .71 & .03 \\
\hline & \multicolumn{5}{|c|}{ Meaningful Condition } \\
\hline $\begin{array}{l}\text { Lo-Lo } \\
\text { Lo-Hi } \\
\text { Hi-Lo } \\
\text { Hi-Hi }\end{array}$ & $\begin{array}{l}.63 \\
.65 \\
.86 \\
.84\end{array}$ & $\begin{array}{l}.78 \\
.92 \\
.60 \\
.81\end{array}$ & $\begin{array}{l}.86 \\
.96 \\
.65 \\
.88\end{array}$ & $\begin{array}{l}.87 \\
.96 \\
.72 \\
.89\end{array}$ & $\begin{array}{r}-.01 \\
.00 \\
-.07 \\
-.01\end{array}$ \\
\hline \multirow[t]{2}{*}{ Average } & .75 & .78 & .82 & .87 & -.05 \\
\hline & \multicolumn{5}{|c|}{ Averages of Word-Pair Types } \\
\hline $\begin{array}{l}\text { Low Cue to Target } \\
\text { High Cue to Target }\end{array}$ & $\begin{array}{l}.46 \\
.74\end{array}$ & $\begin{array}{l}.74 \\
.63\end{array}$ & $\begin{array}{l}.91 \\
.73\end{array}$ & $\begin{array}{l}.84 \\
.75\end{array}$ & $\begin{array}{r}.07 \\
-.02\end{array}$ \\
\hline $\begin{array}{l}\text { Low Target to Cue } \\
\text { High Target to Cue }\end{array}$ & $\begin{array}{l}.59 \\
.61\end{array}$ & $\begin{array}{l}.61 \\
.75\end{array}$ & $\begin{array}{l}.71 \\
.86\end{array}$ & $\begin{array}{l}.73 \\
.84\end{array}$ & $\begin{array}{r}-.02 \\
.02\end{array}$ \\
\hline Overall Average & .60 & .68 & .79 & .79 & .00 \\
\hline
\end{tabular}

Note-These data are from only those subjects who received the recognition test before the cued recall test. 
Bower (1974) and Rabinowitz et al. (1977). In both recall and recognition, it was expected and found that the ease of accessing the encoded event from the retrieval cue was an accurrate predictor of performance. On one level of description, then, we can conceptualize recall and recognition as being fundamentally similar. Differences between these two forms of memory arise when the description of the retrieval cue discriminates between the retrieval cue as it is employed in the recognition test, a nominal copy of the target, and as it is employed in the recall test, a contextual cue. On this second level of description, we can conceptualize recall and recognition as being qualitatively different. Within this framework, it is perfectly reasonable to expect that two types of experimental manipulations can be detected: (1) those that affect the general accessibility of an event (i.e., from a variety of retrieval cues) and thereby lead to correlated recall-recognition performance, and (2) those that affect the ability to access the event only from a specific retrieval cue and thereby lead to uncorrelated recall-recognition performance.

\section{REFERENCE NOTE}

1. Fisher, R. P., \& Craik, F. I. M. The effect of sentence elaboration on recognition memory. Manuscript submitted for publication, 1978.

\section{REFERENCES}

Anderson, J. R., \& Bower, G. H. Recognition and retrieval processes in free recall. Psychological Review, 1972, 79, 97-125.

Anderson, J. R., \& Bower, G. H. A propositional theory of recognition memory. Memory \& Cognition, 1974, 2, 406-412.

Bahrick, H. P. The ebb of retention. Psychological Review, $1965,72,60-73$.

Bartlett, F. C. Remembering. Cambridge, England: Cambridge University Press, 1932.

Craik, F. I. M., \& Lockhart, R. S. Levels of processing: A framework for memory research. Journal of Verbal Learning and Verbal Behavior, 1972, 11, 671-684.

Flexser, A. J., \& Tulving, E. Retrieval independence in recog nition and recall. Psychological Review, 1978, 85, 153-171.

Humphreys, M. S., \& Galbraith, R. C. Forward and backward associations in cued recall: Predictions from the encoding specificity principle. Journal of Experimental Psychology: Human Learning and Memory, 1975, 1, 702-710.

Keppel, G., \& Strand, B. Z. Free-association responses to the primary responses and other responses selected from the Palermo-Jenkins norms. In L. Postman \& G. Keppel (Eds.), Norms of word association. New York: Academic Press, 1970.

Kintsch, W. Learning, memory, and conceptual processes. New York: Wiley, 1970.
Lockhart, R. S., Craik, F. I. M., \& JacoBy, L. L. Depth of processing in recognition and recall: Some aspects of a general memory system. In J. Brown (Ed.), Recall and recognition. London: Wiley, 1976.

MazURYK, G. F., \& Lockhant, R. S. Negative recency and levels of processing in free recall. Canadian Journal of Psychology, 1974, 28, 114-123.

McCormack, P. D. Recognition memory: How complex a retrieval system? Canadian Journal of Psychology, 1972, 26, 18-41.

Palermo, D. S., \& Jenkins, J. J. Word association norms: Grade school through college. Minneapolis: University of Minnesota Press, 1964.

Postman, L., Jenkins, W. O., \& Postman, D. L. An experimental comparison of active recall and recognition. American Journal of Psychology, 1948, 61, 511-519.

Rabinowitz, J. C., Mandler, G., \& Patterson, K. E. Determinants of recognition and recall: Accessibility and generation. Journal of Experimental Psychology: General, 1977, 106, 302-329.

THORNDIKE, E. L., \& LoRge, I. The teacher's word book of 30,000 words. New York: Columbia University Press, 1944.

Tulving, E. Cue-dependent forgetting. American Scientist, 1974, 62, 74-82.

TULVing, E. Ecphoric processes in recall and recognition. In J. Brown (Ed.), Recall and recognition. London: Wiley, 1976.

Tulving, E., \& Thomson, D. M. Encoding specificity and retrieval processes in episodic memory. Psychological Review, $1973,80,352-373$.

Tulving, E., \& Wiseman, S. Relation between recognition and recognition failure of recallable words. Bulletin of the Psychonomic Society, 1975, 6, 79-82.

UNDERWOOD, B. J. Recognition memory for pairs of words as a function of associative context. Journal of Experimental Psychology: Human Learning and Memory, 1976, 2, 404-412.

W AtKins, M. J., \& Tulving, E. Episodic memory: When recognition fails. Journal of Experimental Psychology: General, $1975,104,5-29$.

\section{NOTE}

1. This relation refutes the possible criticism that since this was a mixed-list design, differences among the four word-pair types may have been due to differential study or rehearsal time during acquisition (Underwood, 1976). This turns out to be a pseudoproblem, since the ordering of the four word-pair types differed for the recall and recognition tasks. For example, the Hi-Lo word pairs were relatively well recalled, yet poorly recognized. In order to account for this finding by the differential rehearsal/study-time hypothesis, one must assume that the $\mathrm{Hi}-\mathrm{L}$ o word pairs received much rehearsal/study time during the acquisition stage preceding recall but little study time before the recognition test. This proves to be indefensible, as all subjects received only one acquisition trial, which served for both recall and recognition tests.

(Received for publication August 3, 1978; revision accepted March 16, 1979.) 